\title{
Overview of modern applications of energy storage systems: part I
}

Vencislav Mihaylov

ESO EAD

Sofia, Bulgaria

vencivdm@abv.bg
Valentin Kolev

Faculty of Electrical Engineering

Technical University of Sofia

Sofia, Bulgaria

vkolev@tu-sofia.bg
Dimo Stoilov

Technical University of Sofia; and

Institute for Nuclear Researches

and Nuclear Energy, BAS

Sofia, Bulgaria

dstoilov@tu-sofia.bg

\begin{abstract}
The development of a country and the well-being of its citizens rely heavily on the availability of electricity. Further needs for the improvements of power quality and availability have been the cause for numerous studies and research efforts. During this expansion of energy availability, renewable energy (RE) sources have become popular. The widespread use of RE has however been delayed by its unreliability and fluctuations in output. This problem has however partly been solved by the implementation of energy storage systems (ESS).
\end{abstract}

\section{Keywords — power availability, reliability, energy storage}

\section{INTRODUCTION}

Energy is periodically stored in energy storage devices before being released into the power network. Energy infrastructure and storage technologies could be used to bypass geographic gaps between energy supply and demand. There are currently both fully developed energy storage solutions and ones that still need to be advanced, before becoming useful.

Energy storage devices will be categorized into electrical and thermal types in this article. Both types of technologies can be used to both consume and generate, which could allow them to link split energy markets (fuel, heat and power markets). Energy storage technologies are a means of integrating system with the purpose of improving energy demand, management and supply. Often a singular storage device could be enough to severely improve the local energy services.

The goal of this article is to increase the awareness of industry stakeholders for the potential applications of thermal and electrical energy storage technologies, with the focus firstly on larger energy systems (e.g. an electricity grid) and secondly on off-grid storage applications. It also aims to increase understanding on existing technologies, policies and economic barriers, which are hindering the deployment of energy storage devices. Specific ideas for removing said obstacles shall also be suggested to shareholders in this paper. The article is connected with a second one [1], which explains and analyses the current state of the electrical energy storage technologies.

\section{RATIONALE FOR ENERGY STORAGE}

Energy storage technologies are considered to be both an important tool for achieving a low-carbon future and a valuable component in current energy systems. There are many cases, where the ability to store energy greatly affects an energy providers' competitiveness and makes them unable to provide necessary services.
Before storage devices were mostly created as an investment for scenarios, where variable demand and dispatchable supplies prevail. Today, the focus has shifted more towards the reduction of $\mathrm{CO}_{2}$ emission and the entailing increase in resource use efficiency (e.g. repurposing heat waste through the use of thermal technologies) and to increase the use of renewable energy.

R\&D work is currently being undertaken with the main goal of creating technologies, which would reduce the overall cost and improve the performance of current and emerging storage technologies. At the same time governments and industry stakeholders are attempting to solve non-technical barriers to the use of these technologies. The main causes for the increasing use of energy storage will be:

- the necessity of improving energy use efficiency

- increased use of renewable energy

- increased energy consumption and production of energy

- increased access to electricity (e.g. through the use of solar panels)

- increased focus on the reliability, stability and resilience of electricity grids

- the increased use of electricity in other fields (e.g. the use of electric vehicles).

\section{ENERGY STORAGE APPLICATIONS}

Energy storage technologies can be used to provide support for supply, transportation and distribution infrastructure. These technologies could provide significant advantages to supply and/or demand system operators. While there is no lack in energy demand, supply is more of a concern in the modern day renewable energy focused markets. Some typical energy storage technology applications are listed below in Table1. 
Table 1: "Key characteristics of storage systems for particular applications in the energy system" [11])

\begin{tabular}{|c|c|c|c|c|c|}
\hline Application & $\begin{array}{c}\text { Output (electriclty, } \\
\text { thermal) }\end{array}$ & Slze (MW) & $\begin{array}{l}\text { Discharge } \\
\text { duration }\end{array}$ & $\begin{array}{c}\text { Cycles } \\
\text { (typlcal) }\end{array}$ & Response time \\
\hline Seasonal storage & $\mathrm{e}, \mathrm{t}$ & 500 to 2000 & $\begin{array}{l}\text { Days to } \\
\text { months }\end{array}$ & $\begin{array}{c}1 \text { to } \\
5 \text { per year }\end{array}$ & day \\
\hline Arbitrage & e & 100 to 2000 & $\begin{array}{c}8 \text { hours to } \\
24 \text { hours }\end{array}$ & $\begin{array}{l}0.25 \text { to } \\
1 \text { per day }\end{array}$ & $>1$ hour \\
\hline Frequency regulation & e & 1 to 2000 & $\begin{array}{l}1 \text { minute to } 15 \\
\text { minutes }\end{array}$ & $\begin{array}{c}20 \text { to } \\
40 \text { per day }\end{array}$ & $1 \mathrm{~min}$ \\
\hline Load following & $e, t$ & 1 to 2000 & $\begin{array}{c}15 \text { minutes to } \\
1 \text { day }\end{array}$ & $\begin{array}{c}1 \text { to } 29 \text { per } \\
\text { day }\end{array}$ & $<15 \min$ \\
\hline Voltage support & e & 1 to 40 & $\begin{array}{l}1 \text { second to } \\
1 \text { minute }\end{array}$ & $\begin{array}{l}10 \text { to } 100 \\
\text { per day }\end{array}$ & $\begin{array}{l}\text { millisecond } \\
\text { to second }\end{array}$ \\
\hline Black start & e & 0.1 to 400 & $\begin{array}{l}1 \text { hour to } \\
4 \text { hours }\end{array}$ & $<1$ per year & $<1$ hour \\
\hline $\begin{array}{l}\text { Transmission and } \\
\text { Distribution (T\&D) } \\
\text { congestion relief }\end{array}$ & $e, t$ & 10 to 500 & $\begin{array}{c}2 \text { hours to } \\
4 \text { hours }\end{array}$ & $\begin{array}{c}0.14 \text { to } \\
1.25 \text { per day }\end{array}$ & sthour \\
\hline $\begin{array}{l}\text { T\&D infrastructure } \\
\text { investment deferral }\end{array}$ & $e, t$ & 1 to 500 & $\begin{array}{l}2 \text { hours to } \\
5 \text { hours }\end{array}$ & $\begin{array}{c}0.75 \text { to } \\
1.25 \text { per day }\end{array}$ & sthour \\
\hline $\begin{array}{l}\text { Demand shifting and peak } \\
\text { reduction }\end{array}$ & $e, t$ & 0.001 to 1 & $\begin{array}{l}\text { Minutes to } \\
\text { hours }\end{array}$ & $\begin{array}{c}1 \text { to } \\
29 \text { per day }\end{array}$ & $<15 \mathrm{~min}$ \\
\hline Off-grid & $e, t$ & 0.001 to 0.01 & $\begin{array}{l}3 \text { hours to } \\
5 \text { hours }\end{array}$ & $\begin{array}{l}0.75 \text { to } 1.5 \\
\text { per day }\end{array}$ & $<1$ hour \\
\hline $\begin{array}{l}\text { Variable supply resource } \\
\text { integration }\end{array}$ & $e, t$ & 1 to 400 & $\begin{array}{l}1 \text { minute to } \\
\text { hours }\end{array}$ & $\begin{array}{c}0.5 \text { to } \\
2 \text { per day }\end{array}$ & $<15 \mathrm{~min}$ \\
\hline Waste heat utilisation & $t$ & 1 to 10 & $\begin{array}{l}1 \text { hour to } \\
1 \text { day }\end{array}$ & $\begin{array}{c}1 \text { to } \\
20 \text { per day }\end{array}$ & $<10 \mathrm{~min}$ \\
\hline Combined heat and power & $t$ & 1 to 5 & $\begin{array}{l}\text { Minutes to } \\
\text { hours }\end{array}$ & $\begin{array}{c}1 \text { to } \\
10 \text { per day }\end{array}$ & $<15 \mathrm{~min}$ \\
\hline Spinning reserve & e & 10 to 2000 & $\begin{array}{l}15 \text { minutes to } \\
2 \text { hours }\end{array}$ & $\begin{array}{l}0.5 \text { to } \\
2 \text { per day }\end{array}$ & $<15 \mathrm{~min}$ \\
\hline Non-spinning reserve & e & 10 to 2000 & $\begin{array}{l}15 \text { minutes to } \\
2 \text { hours }\end{array}$ & $\begin{array}{c}0.5 \text { to } \\
2 \text { per day }\end{array}$ & $<15 \mathrm{~min}$ \\
\hline
\end{tabular}

Sources: IEA (20142), Energy Technology Perspectives, forthcoming, OECD/IEA, Paris, France. EPRI (Eloctric Power Rosoarch Instituto) (2010), Eloctricali Enorgy Storage Tochnology Options", Roport, EPRl, Palo Aito, California. Bl

Some additional explanations could be found in the Appendix.

\section{KEY APPLICATION DEFINITIONS}

\section{Seasonal storage}

"The ability to store energy for days, weeks, or months to compensate for a longer-term supply disruption or seasonal variability on the supply and demand sides of the energy system (e.g.) storing heat in the summer to use in the winter via underground thermal energy storage systems)." [11]

\section{Arbitrage/Storage trades}

"Storing low-priced energy during periods of low demand and subsequently selling it during high- priced periods within the same market is referred to as a storage trade. Similarly, arbitrage refers to this type of energy trade between two energy markets." [11]

\section{Frequency regulation}

"The balancing of continuously shifting supply and demand within a control area under normal conditions is referred to as frequency regulation. Management is frequently done automatically, on a minute-to-minute (or shorter) basis." [11]
"The second continuous electricity balancing mechanism for operation under normal conditions, following frequency regulation, is load following. Load following manages system fluctuations on a time frame that can range from 15 minutes to 24 hours, and can be controlled through automatic generation control, or manually." [11]

\section{Voltage support}

"The injection or absorption of reactive power to maintain voltage levels in the transmission and distribution system under normal conditions is referred to as voltage support." [11]

\section{Black start}

"In the rare situation when the power system collapses and all other ancillary mechanisms have failed, black start capabilities allow electricity supply resources to restart without pulling electricity from the grid." [11]

\section{T\&D congestion relief and deferral of infrastructure investments}

"Energy storage technologies use to temporally and/or geographically shifting energy supply or demand in order to relieve congestion points in the transmission and distribution (T\&D) grids or to defer the need for a large investment in T\&D infrastructure." [11]

\section{Shifting of demand and peak reduction}

"Energy demand can be shifted to relieve strain from supply sources. These shifts are facilitated by changing the time at which certain activities take place (e.g. the heating of water or space) and can be directly used to actively facilitate a reduction in the maximum (peak) energy demand level" [11]).

\section{Off-grid}

"Off-grid energy consumers frequently rely on fossil or renewable resources (including variable renewables) to provide heat and electricity. To ensure reliable off-grid energy supplies and to support increasing levels of local resources use, energy storage can be used to fill gaps between variable supply resources and demand." [11]

\section{Variable supply resource integration}

"The use of energy storage to change and optimise the output from variable supply resources (e.g. wind, solar), mitigating rapid and seasonal output changes and bridging both temporal and geographic gaps between supply and demand in order to increase supply quality and value." [11])

\section{Waste heat utilisation}

"Energy storage technology use for the temporal and geographic decoupling of heat supply (e.g. CHP facilities, thermal power plants) and demand (e.g.) for heating/cooling buildings, supplying industrial process heat) in order to utilise previously wasted heat." [11] 


\section{Combined heat and power}

"Electricity and thermal energy storage can be used in combined heat and power (CHP) facilities in order to bridge temporal gaps between electricity and thermal demand." [11]

\section{Spinning and non-spinning reserve}

"Reserve capacity for the electricity supply is used to compensate for a rapid, unexpected loss in generation resources in order to keep the system balanced. This reserve capacity is classified according to the response time at rotating $(<15$ minutes response time) and non-rotating ( $>15$ minutes response time). Faster response times are usually more valuable to the system. In some regions, the reserve capacity is called the "frequency limitation reserve." [11])

Some additional explanations could be found in the Appendix. There are presented also two useful illustrative cases.

\section{BENEFITS- STACKING}

Benefits-stacking is a situation, where extra revenue is gained from utilizing systems or technologies for multiple applications. The capability for one such technology to provide and manage the applications, which fit into the benefit stack is measured as compatibility.

Technical potential is the means of evaluating the suitability of a system or technology for a given task. "For electricity storage, discharge period, response time and power rating provide a good first indicator on suitability. For thermal storage, storage output temperature and capacity can be used as a starting point in determining suitability for particular applications [17]. "In Figure 1 , power requirements are plotted in relationship with energy requirements to illustrate the combinations that are most suited to certain applications.

Near-term suitability could also be broadly determined by considering the characteristics of the current energy system, as shown in Table 2" [11].

"Figure 1: Power requirement versus discharge duration for some applications in today's energy system" [11], [12], [13], [14], [15],

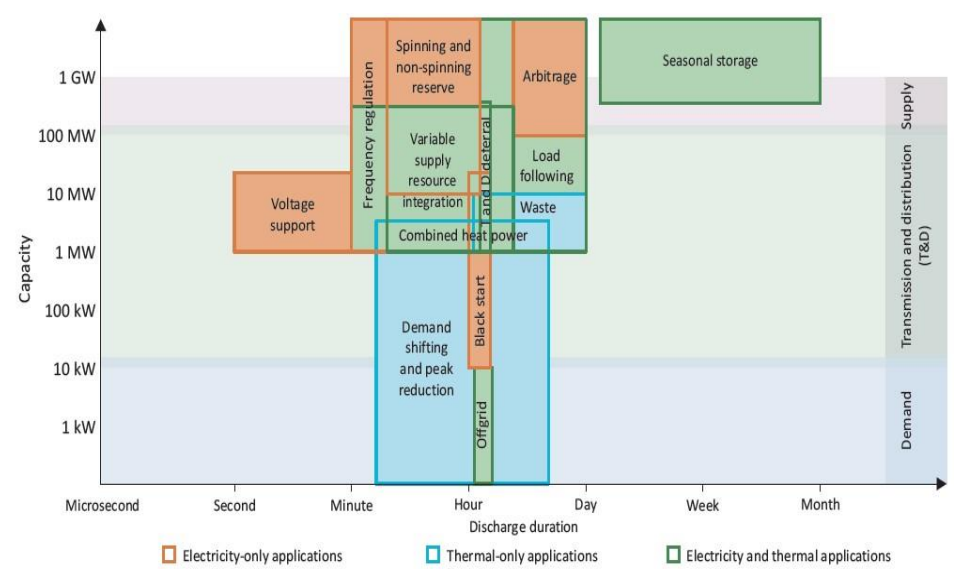

"Table 2: Near-term suitability criteria for determining prime energy storage technologies for deployment" [11]

\begin{tabular}{l|l|l|}
\hline Energy storage technology & \multicolumn{1}{|c}{ Technology examples } & $\begin{array}{c}\text { Might provide the most near-term } \\
\text { benefits in areas with: }\end{array}$ \\
\hline Large-scale electricity & $\begin{array}{l}\text { pumped-storage hydropower (PSH), } \\
\text { compressed air energy storage (CAES), } \\
\text { flywheels }\end{array}$ & $\begin{array}{l}\text { developed electricity grids that can } \\
\text { more easily accommodate centralised } \\
\text { energy supply resources }\end{array}$ \\
\hline $\begin{array}{l}\text { Large-scale thermal } \\
\text { (UTES), molten salts }\end{array}$ & batteries & $\begin{array}{l}\text { significant waste heat resources, } \\
\text { concentrated heating or cooling } \\
\text { demand, or large amounts of } \\
\text { concentrating solar power (CSP) }\end{array}$ \\
\hline Small-scale electricity & ice storage, hot and cold-water tanks & $\begin{array}{l}\text { remote and off-grid communities as } \\
\text { well as those looking to diversify their } \\
\text { transportation fuel resource demand }\end{array}$ \\
\hline Small-scale thermal & $\begin{array}{l}\text { higher demand variability (i.e. more } \\
\text { "peak-y" demand - lots of hot or cold } \\
\text { needed at one time or another) }\end{array}$ \\
\hline
\end{tabular}

\section{LOCATIONS}

Energy storage devices can be deployed throughout the entire network - in the supplier, transportation, distribution and end-user portions (Figure 2). It is vital to choose the location of said devices based on their planned utilization and also to account for current and upcoming smart grid and other such infrastructure technologies. Figure 2 shows a hypothetical deployment plan for said storage technologies throughout the electricity grid.

"Figure 2: Hypothetical deployment of storage assets across an electric power system” [16]

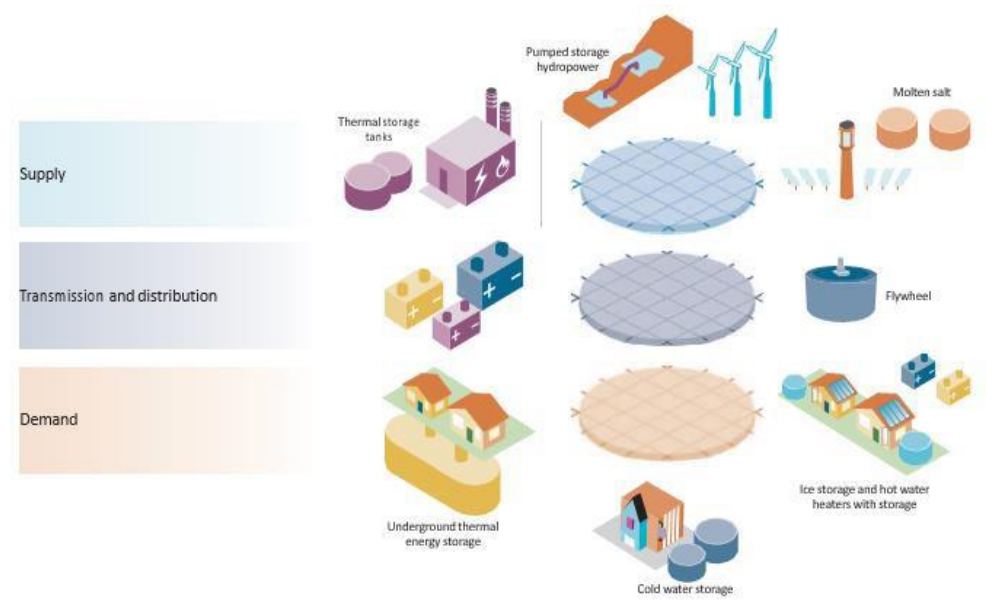

\section{CONCLUSION}

Among the potential performance benefits of advanced energy storage applications are improved system reliability, dynamic stability, increased power quality, improved transmission capacity and zone protection. The energy storage device can also have a positive impact on the environment and costs by reducing fuel consumption and emissions through reduced linear losses and reduced availability of frequency stabilization generators.

As deregulation takes place, production and transmission resources will be used at higher levels of efficiency, leading to stricter and momentarily controlled reserve capacity. Energy storage devices can facilitate this process by allowing maximum use of useful resources. 


\section{APPENDIX}

Explanation 1(Concerning point III.ENERGY STORAGE APPLICATIONS): "Energy versus power applications for electricity storage technologies: Applications for electricity storage technologies can be discussed in terms of power applications versus energy applications" [11] "Power applications refer to those requiring a highpower output for a relatively short period of time (e.g. seconds or minutes). Energy applications require discharge of many minutes to several hours at or near the storage system's nominal power rating" [11].

Explanation 2(Concerning point IV.KEY APPLICATION DEFINITIONS): "Potential use of thermal storage in CHP plants to support the integration of renewable energy resources: increased operational flexibility in CHP plants through enabled decoupling of the heat demand of a connected district heating system and the requirements of the electricity system [11].

"Furthermore, the increased flexibility afforded by both thermal and electricity storage in CHP facilities could enable higher levels of participation in balancing power markets" [11].

"Thermal storage, in the context of district heating, stores heat in the form of hot water in tanks. In atmospheric storage systems, the water temperature lies just below the boiling point at around $95^{\circ} \mathrm{C}$ to $98^{\circ} \mathrm{C} "$ [11]).

"Pressurised tanks typically store water at temperatures of between $120^{\circ} \mathrm{C}$ and $130^{\circ} \mathrm{C}$. The size of such storage tanks ranges from 100 up to $50000 \mathrm{~m} 3$ in volume, which corresponds to heat storage capacities from approximately 10 megawatt hours (MWh) to 2 gigawatt hours (GWh) per load cycle" [11].

"Storage facilities that store energy at atmospheric pressure have comparatively lower investment costs than pressurised ones. However, the pressurised storage technologies show a $30 \%$ to $40 \%$ higher specific storage capacity per volume" [11].

“Today's thermal storage facilities focus on reducing the operation of peak load boilers and avoiding costly restarting processes" [11].

"Furthermore, in the presence of district heating networks, heat price can have a significant impact on the choice of the CHP plant's business model. In the case of rapidly increasing use of renewable energy resources, $\mathrm{CHP}$ is poised to operate primarily in one of two strategies" [11].
Useful illustrative cases (Concerning point IV.KEY APPLICATION DEFINITIONS):

Case A

High electricity prices

High residual load*

Residual heat from energy production is rerouted into the district heating network through the use of charged thermal storage systems.

However, electricity and heat production are closely coupled, which in turn causes a situation, where, if the heat demands increases, then electricity production decreases. Thermal storage helps to secure increased electricity production, when heat demand is low (and vice versa).

Case B

Low electricity prices

Low or negative residual load

In this scenario, the production costs of electricity is higher than the sales price, which forces the CHP to be run at minimal capacity or shut down. Heat demand in this scenario is met with previously stored thermal energy.

In this scenario the implementation of electric heating systems (power to heat) may be viable and, in turn, provide a means of converting excess renewable energy into heat energy for the district.

\footnotetext{
* "Residual load is defined as the electricity demand minus the amount supplied by renewable energy" [11].
} 


\section{REFERENCES}

[1] Mihaylov V., Kolev V., Stoilov D., Overview of modern applications of energy storage systems: part II, Science conference BulEF2020

[2] https://energystorageforum .com/energy-storagetechnologies/applications-of-energy-storage

[3] https://www.sciencedirekt.com/topics/engineering-energystorage-technology

[4] https://www.ucsusa.org/resources/how-energy-storage-works

[5] https://www.pnas.org/content/117/23/12550

[6] https://www.world-nuclear.org/information-library/current-andfuture-generation/electricity0and-energy-storage.aspx

[7] https://energystorage,org/why-energy-sterage/technologies/

[8]https://elearn.edu.vn/ielltsppracticereading.aspx?practiced=3\&sbje ctid $=8 \&$ isprac $=1 \&$ detailed $=0 \&$ spage $=1 \&$ type menu $=5$

[9] https://www.scienscedirect.com/topics/engineering-combinetheat-and-power-plant

[10] https://arxiv.org/abs/1702.06005

[11] Modified from IEA (2014) Energy technology perspectives, OECD/IEA. Paris, France
[12] BATTKE, T.S. Shmidt, D. Grosspietsch and V.H. Hoffmann (2013), "A review and probabilistic model of life cycle costs of stationary batteries in multiple applications", Renewable and sustainable energy reviews Vol.25, PP. 240 -250

[13] EPRI (Electric power research institute) (2010), "Electrical energy storage technology options", Report, EPRI, Palo Alto, CA, United States.

[14] Sandia national laboratories (2010), Energy storage for the electricity grid: benefit and market potential assessment suide, A study for the doe energy storage systems, Albuqerque, NM and Livemore, CA, United States.

[15] IEA-ETSAP (Energy technology systems analtsis programme) and IRENA (2013), "Thermal energy storage" Technology BRIEF E17, Bonn, Germany

[16] Modified from EIA (Energy information administration) (2012), "Electricity storage: lokatin...and cost", Today in energy, Washington, DC, United States, www.IEA.gov/todayinenergy/detail.

[17] Hauer, Quinnell and Lävemann, 2013 